\title{
Ultra-Rapid Lispro Efficacy and Safety Compared to Humalog@ in Japanese Patients With Type 2 Diabetes: PRONTO-T2D Subpopulation Analysis
}

\author{
Hideaki Jinnouchi · Makoto Imori · Hiroshi Nishiyama • \\ Takeshi Imaoka
}

Received: March 27, 2020 / Published online: July 29, 2020

(C) The Author(s) 2020

\section{ABSTRACT}

Introduction: The aim of this study was to evaluate the efficacy and safety of ultra-rapid lispro (URLi) versus lispro in a subgroup analysis of Japanese adults with type 2 diabetes mellitus (T2DM) from the phase 3 PRONTO-T2D trial.

Methods: After an 8-week lead-in period during which patients transitioned to insulin lispro 3 times a day before main meals in association with basal insulin (glargine or degludec), the patients were randomized to 26 weeks of double-blind URLi or lispro injected immediately prior to meals. The primary endpoint was change in hemoglobin A1c (HbA1c) from baseline to week 26 between URLi and lispro. The multiplicity-adjusted objectives were 1- and 2-h postprandial glucose (PPG) excursions after a test meal and change in $\mathrm{HbA1c}$ from baseline to week 26 in the URLi and lispro groups.

Results: Results were obtained from prespecified exploratory analyses of 26-week data in

Digital Features To view digital features for this article go to https://doi.org/10.6084/m9.figshare.12657071.

H. Jinnouchi

Jinnouchi Hospital, 6 Chome-2-3 Kuhonji, Chuo

Ward, Kumamoto 862-0976, Japan

M. Imori $(\bowtie) \cdot H$. Nishiyama · T. Imaoka Medicines Development Unit Japan and Medical Affairs, Eli Lilly Japan K.K, 5-1-28, Isogami-dori, Chuo-ku, Kobe, Hyogo 651-0086, Japan e-mail: imori_makoto@lilly.com
Japanese patients randomized to receive URLi $(n=47)$ or lispro $(n=46)$. Mean baseline HbA1c levels significantly improved during the lead-in period to a baseline value of $7.50 \%$ and $7.60 \%$ in patients subsequently randomized to the URLi and lispro treatment groups, respectively. At week 26, the least squares mean (LSM) difference in HbAc1 between the URLi and lispro groups was $0.13 \%$ (95\% confidence interval [CI] -0.12 to 0.39$)(1.4 \mathrm{mmol} / \mathrm{mol}, 95 \% \mathrm{CI}-1.3$ to 4.2). Although there were no significant differences in PPG excursions at any time-point, numerically smaller PPG excursions were consistently observed from $30 \mathrm{~min}$ to $3 \mathrm{~h}$ during the mixed-meal tolerance test in patients on URLi compared to those on lispro. LSM differences in PPG excursions at week 26 were $-10.5 \mathrm{mg} / \mathrm{dL} \quad(95 \% \quad \mathrm{CI}-32.7$ to 11.7$)$ $(-0.58 \mathrm{mmol} / \mathrm{L}, 95 \% \mathrm{CI}-1.82$ to 0.65$)$ at $1 \mathrm{~h}$ and $-14.9 \mathrm{mg} / \mathrm{dL}(95 \% \mathrm{CI}-40.3$ to 10.5$)$ $(-0.83 \mathrm{mmol} / \mathrm{L}, 95 \% \mathrm{CI}-2.24$ to 0.58$)$ at $2 \mathrm{~h}$. There were no significant differences between treatments in rates of severe/overall hypoglycemia or incidence of treatment-emergent adverse events.

Conclusions: URLi administered as prandial insulin in combination with basal insulin provides effective glycemic control when administered immediately before a meal in Japanese patients with T2DM. URLi was well tolerated in this population.

Trial Registration: ClinicalTrials.gov, NCT0 3214380. 
Keywords: Hemoglobin A1c; Humalog; Japan; Mixed-meal tolerance test; Postprandial hyperglycemia; Type 2 diabetes mellitus; Ultrarapid lispro

\section{Key Summary Points}

\section{Why carry out this study?}

The prevalence of diabetes in Japan is increasing and there is an medical need for the development and official approval of rapid-acting insulins.

We evaluated the efficacy and safety of ultra-rapid lispro (URLi) in comparison to Humalog ${ }^{\circledR}$ (lispro) in Japanese patients with T2DM in a phase 3, randomized, subpopulation analysis.

\section{What was learned from the study?}

URLi and lispro provide effective and comparable glycemic control (including postprandial glycemic control).

URLi provides effective glycemic control in Japanese patients with type 2 diabetes and is well tolerated.

\section{INTRODUCTION}

The vast majority of people with diabetes have type 2 diabetes mellitus (T2DM), and the increasing global prevalence of T2DM represents a worldwide health burden [1]. Adequate blood glucose control is important for preventing diabetic complications and cardiovascular disease, and for reducing the medical and public health burden of T2DM [1]. For patients with T2DM, reaching and maintaining glycemic goals remain challenging, with many patients experiencing difficulties [2, 3] achieving the target hemoglobin A1c (HbA1c) of $<7 \%$ [3]. In Japan, where the prevalence of diabetes is increasing [4], the mean HbA1c of patients with T2DM is $7.03 \%$ [5], with only approximately
$50 \%$ of patients reaching the recommended target [5].

Control of both fasting and postprandial hyperglycemia is essential to reach HbA1c goals. It has been demonstrated that postprandial hyperglycemia contributes to overall glucose control as assessed by $\mathrm{HbA1c}$, and increases the risk of micro- and macrovascular complications and death in diabetic patients [6-10]. There is substantial evidence to support the association of postprandial glucose (PPG) levels with the development of complications in T2DM [11]. However, control of postprandial hyperglycemia continues to be a challenge [12] in the overall treatment of T2DM patients, with increased PPG levels significantly associated with increased healthcare resource utilization [13]. Currently available rapid-acting insulins were developed to manage PPG levels [14-18] and have been found to be a superior treatment for lowering postprandial glycemic excursions $[15,19]$.

Lispro (Humalog ${ }^{\circledR}$; Eli Lilly and Company) is a commercially available, rapid-acting human insulin analogue indicated to improve glycemic control in patients with diabetes mellitus [20]. Fast-acting insulin aspart (Fiasp ${ }^{\circledR}$; Eli Lilly and Company) is a formulation of the rapid-acting insulin analogue insulin aspart that was recently approved for the treatment of T2DM in Japan (September 2019). Ultra-rapid lispro (URLi; intervention study name LY900014) is a newly developed insulin lispro formulation that utilizes two enabling excipients, treprostinil and citrate, each with an independent mechanism, to accelerate the absorption of the insulin lispro. Treprostinil is used in microdose quantities in the formulation of URLi but is not detectable in clinical doses in the systemic circulation, nor is it associated with systemic effects. URLi was formulated to more closely mimic the physiological prandial insulin secretion pattern, and the expectation is that it will control PPG excursions more effectively than lispro.

PRONTO-T2D was a recent, prospective, randomized, double-blind phase 3 trial in adults with T2DM which compared URLi to lispro, in combination with insulin glargine or insulin degludec [21]. This pivotal study demonstrated 
that URLi was non-inferior to lispro in maintaining glycemic control [21]. Here we describe a Japanese subpopulation analysis of the PRONTO-T2D trial. The aim of this subpopulation analysis was to evaluate the efficacy and safety of URLi administered at mealtime, in comparison to lispro, in Japanese patients with T2DM.

\section{METHODS}

\section{Study Participants}

The study design has been described previously [21]. Briefly, adults with clinically diagnosed T2DM (based on the World Health Organization classification [22]) for at least 1 year prior to screening and with HbA1c levels between 7.0\% $(53.0 \mathrm{mmol} / \mathrm{mol})$ and $10.0 \%(85.8 \mathrm{mmol} / \mathrm{mol})$ inclusive were eligible to participate. Exclusion criteria included hypoglycemia unawareness, as assessed by an investigator, $\geq 1$ event of severe hypoglycemia requiring medical assistance, diabetic ketoacidosis or a hyperglycemic hyperosmolar state within 6 months prior to screening.

\section{Study Design}

PRONTO-T2D was a phase 3, prospective, randomized, double-blind, outpatient, multinational, multicenter, two-group, parallel, activecontrolled study conducted in patients with T2DM which compared URLi to insulin lispro, in combination with basal insulin. URLi and lispro were administered immediately ( $0-2 \mathrm{~min})$ prior to each meal in combination with insulin degludec or glargine. Patients were able to continue their therapy with metformin and/or sodium-glucose cotransporter- 2 inhibitor throughout the study. Randomization was followed by 26 weeks of treatment and a 4-week safety follow-up period. Here we report the results of a prespecified subpopulation analysis of Japanese patients from the PRONTO-T2D trial. The study design is outlined in Fig. 1.

The study was conducted in accordance with the International Council for Harmonization Guidelines for Good Clinical Practice, including the Declaration of Helsinki and its later amendments, and the Council for International Organization of Medical Sciences International Ethical Guidelines. An Ethical Review Board at each site (Kobori Clinic, H.E.C. Science Clinic, Jinnouchi Hospital, Heiwadai Hospital, The Institute for Adult Diseases, Naka Memorial Clinic, Tomonaga Clinic, Nihonbashi Sakura Clinic, AMC Nishi-umeda Clinic, Manda Hospital, Fukuoka Red Cross Hospital, Shin Akasaka Clinic, Shinagawa East One Medical Clinic, Sasebo Chuo Hospital, Okuguchi Clinic of Internal Medicine, Sapporo Skin Clinic, Takatsuki Red Cross Hospital, Osaka City University Medical School Hospital, Goshogatani Home Clinic, Tokyo Women's Medical University Hospital) approved all procedures, and all subjects provided written, informed consent.

\section{Study Interventions and Randomization}

The study consisted of an 8-week lead-in period during which time patients transitioned to insulin lispro 3 times a day before main meals in combination with basal insulin (glargine or degludec). Following the lead-in period, patients were randomized to one of two treatment groups in a 1:1 ratio, URLi $100 \mathrm{U} / \mathrm{mL}$ or lispro $100 \mathrm{U} / \mathrm{mL}$, administered $0-2$ min prior to the start of each meal. Following randomization, the prandial insulin dose was adjusted as necessary during the initial 12 weeks in a treatto-target manner to self-monitored blood glucose (SMBG) levels of 80 to $<110 \mathrm{mg} / \mathrm{dL}(4.4-$ $6.1 \mathrm{mmol} / \mathrm{L}$ ) fasting or premeal, $90-130 \mathrm{mg} / \mathrm{dL}$ (5.0-7.2 $\mathrm{mmol} / \mathrm{L})$ bedtime and $<140 \mathrm{mg} / \mathrm{dL}$ $(<7.8 \mathrm{mmol} / \mathrm{L}) 1-2 \mathrm{~h}$ postmeal. Patients were able to use the carbohydrate counting method or the pattern adjustment method to adjust their insulin dose. During weeks 12-26 of treatment, adjustments to prandial and basal insulin doses were only performed to maintain glycemic control or for safety reasons, such as hypoglycemia or unacceptable hyperglycemia.

\section{Standardized Meal Test}

All participants underwent a 4-h mixed-meal tolerance test (MMTT) at baseline and at the 


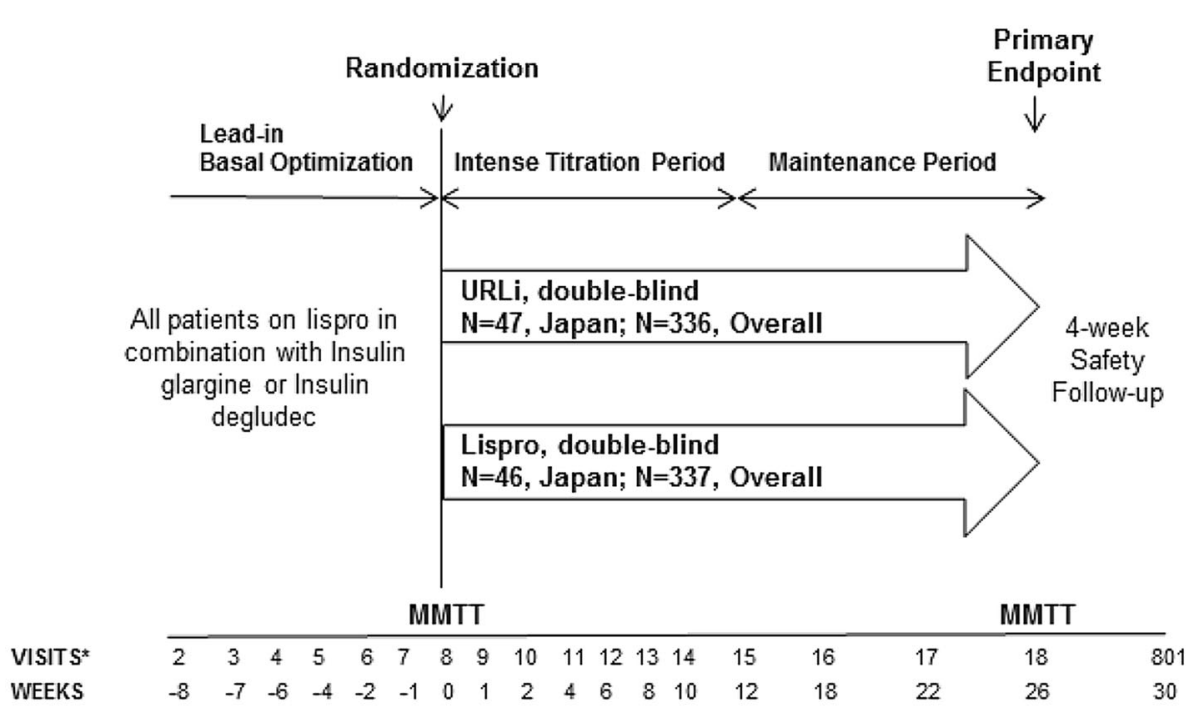

*Visits $3,4,6,9,12,14$ were telephone visits

Fig. 1 Study design. Following a 1-week screening period and an 8-week lead-in period, Japanese patients were randomized in a $1: 1$ ratio to receive ultra-rapid lispro (URLi) or lispro for 26 weeks, administered immediately (0-2 min) prior to each meal in combination with insulin

end of the 26-week treatment period. The MMTT meal (700 kcal including approximately $100 \mathrm{~g}$ of carbohydrate) consisted of a liquid nutrition shake and had to be consumed within $15 \mathrm{~min}$.

\section{Self-Monitored Blood Glucose}

All study participants were instructed to perform three sets of 10-point SMBG profiles prior to five visits (baseline, weeks 4, 8, 12, and 26). Participants were also instructed to measure a minimum of four SMBG readings daily (morning, midday and evening premeal and prebedtime), with additional SMBG readings as needed for glucose self-management.

\section{Study Endpoints}

The primary endpoint was the change in HbA1c from baseline to week 26 . Key secondary endpoints were 1- and 2-h PPG excursions during the MMTT. Other secondary endpoints degludec or glargine. All patients underwent a 4-h mixedmeal tolerance test $(M M T T)$ at baseline (week 0 , visit 8) and at the end of primary treatment period (week 26, visit 18). $N$ Number of patients

included the percentage of patients who achieved the target HbA1c, 10-point SMBG values and safety measurements.

\section{Statistical Analysis}

The efficacy analysis was conducted as previously described for the overall population [21]. These methods were applied to the Japanese population in a prespecified subset analysis, although statistical power was not taken into consideration, and $p$ values are provided as a reference.

\section{Safety Analysis}

Safety measures included adverse events (AEs), hypoglycemia and weight. When statistical comparisons were applied, the Fisher's exact test was employed. Severe hypoglycemia (an episode requiring assistance due to neurological impairment as confirmed by the investigator) 
was reported as a severe $\mathrm{AE}$ (SAE) and summarized by rate and incidence.

\section{RESULTS}

\section{Study Participants in the Japanese Subpopulation}

The Japanese subpopulation comprised 93 patients of the 673 randomized patients in the overall patient population of the PRONTO-T2D trial. Of these 93 patients, 47 were randomized to the URLi treatment arm and 46 were randomized to the lispro treatment arm. All Japanese patients completed the study. Baseline patient characteristics are outlined in Table 1. Overall, baseline characteristics were similar between the treatment groups with the exception of gender: there were more males in the URLi treatment arm than in the lispro treatment arem ( 83.0 vs. $58.7 \%$, respectively).

\section{Efficacy}

\section{Glycated hemoglobin}

The primary study endpoint was the change in HbA1c from baseline to week 26. For the overall patient population of the PRONTO-T2D trial, non-inferiority of URLi to lispro was confirmed in the change in $\mathrm{HbA1c}$ from baseline to week 26 [21] (the upper 95\% confidence interval [CI] of least squares mean [LSM] difference was $<0.4 \%$, defined as the prespecified non-inferiority criteria for the overall population).

In the Japanese patients of our subanalysis, the mean $\mathrm{HbA1c}$ at study entry was $8.1 \%$ $(64.5 \mathrm{mmol} / \mathrm{mol})$ and $8.1 \%(65.3 \mathrm{mmol} / \mathrm{mol})$ for patients randomized at baseline (i.e. end of lead-in period) to the URLi and lispro treatment arms, respectively. The mean HbA1c improved during the lead-in period, during which time all patients were treated with lispro plus basal insulin (degludec or glargine), to baseline values of $7.5 \%(58.5 \mathrm{mmol} / \mathrm{mol})$ for patients randomized to the URLi treatment group and $7.6 \%$ $(59.5 \mathrm{mmol} / \mathrm{mol})$ for patients randomized to the lispro treatment group. The changes in the LSM from baseline to week 26 was $-0.22 \%$
$(-2.4 \mathrm{mmol} / \mathrm{mol})$ for the URLi group and $-0.35 \%(-3.9 \mathrm{mmol} / \mathrm{mol})$ for the lispro group. At week 26, the LSM difference between the URLi and lispro treatment groups was $0.13 \%$ (95\% CI -0.12 to 0.39$)(1.4 \mathrm{mmol} / \mathrm{mol}, 95 \% \mathrm{CI}$ -1.3 to 4.2 ). HbA1c levels at baseline and at weeks $4,8,12$ and 26 are shown in Fig. 2 .

At week 26 , the HbA1c target of $<7.0 \%$ was achieved by 15 of the 47 patients (31.91\%) in the URLi treatment arm and by 14 of the 46 patients $(30.43 \%)$ in the lispro treatment arm (odds ratio [OR] 1.10, 95\% CI 0.42-2.87), and the HbA1c target of $\leq 6.5 \%$ was achieved by eight $(17.02 \%)$ and eight (17.39\%) patients in these treatment arms, respectively (OR 0.99, 95\% CI 0.33-2.96).

\section{Meal Test/Postprandial Excursions}

In this Japanese subpopulation, there were no statistically significant differences at week 26 in PPG excursions between the URLi and lispro treatment arms at $1 \mathrm{~h}$ postmeal (LSM differences $-10.5 \mathrm{mg} / \mathrm{dL}, 95 \%$ CI -32.7 to 11.7 [ $-0.58 \mathrm{mmol} / \mathrm{L}, 95 \% \mathrm{CI}-1.82$ to 0.65$]$ ) or $2 \mathrm{~h}$ postmeal (LSM differences - $14.9 \mathrm{mg} / \mathrm{dL}, 95 \%$ CI -40.3 to 10.5 [- $-0.83 \mathrm{mmol} / \mathrm{L}, 95 \%$ CI -2.24 to 0.58]). Although treatment with mealtime URLi and lispro did not result in significant differences at week 26 in terms of controlling PPG excursions, consistent numerically smaller excursions were observed for URLi at time-points ranging from $30 \mathrm{~min}$ to $3 \mathrm{~h}$ after the meal. The mean insulin dose during the MMTT at week 26 was similar between the URLi $(8.9 \mathrm{U} / \mathrm{mL}[0.12 \mathrm{U} / \mathrm{kg}])$ and lispro $(10.7 \mathrm{U} / \mathrm{mL}$ $[0.14 \mathrm{U} / \mathrm{kg}])$ treatment groups. PPG excursions during the MMTT at week 26 for both treatment groups is shown in Fig. 3.

A reduction in the incremental area under the serum glucose concentration-time curve (iAUC), above the glucose level at the start of MMTT, was observed during the MMTT for URLi in comparison to lispro at all measured time intervals from $30 \mathrm{~min}$ to $4 \mathrm{~h}(0-30 \mathrm{~min}$, 0-1 h, 0-2 h, 0-3 h, 0-4 h). Serum glucose iAUC at all time intervals during the 4-h MMTT at 26 weeks was statistically significantly lower in the URLi group than in the lispro group. 
Table 1 Baseline characteristics in the subpopulation of Japanese patients from the PRONTO-T2D trial

\begin{tabular}{|c|c|c|c|}
\hline \multirow[t]{2}{*}{ Patient characteristics } & \multicolumn{2}{|l|}{ Treatment arm } & \multirow[t]{2}{*}{ Total study population $(N=93)$} \\
\hline & URLi $(N=47)$ & Lispro $(N=46)$ & \\
\hline Age (years) & $58.7(9.6)$ & $59.5(9.3)$ & $59.1(9.4)$ \\
\hline Gender, male, $n(\%)$ & $39(83.0)$ & $27(58.7)$ & $66(71.0)$ \\
\hline Weight $(\mathrm{kg})$ & $73.3(13.0)$ & $73.2(14.6)$ & $73.2(13.7)$ \\
\hline Body mass index $\left(\mathrm{kg} / \mathrm{m}^{2}\right)$ & $26.2(3.6)$ & $27.8(5.1)$ & $27.0(4.4)$ \\
\hline Duration of T2DM (years) & $17.3(8.3)$ & $16.2(8.0)$ & $16.8(8.1)$ \\
\hline HbAlc at study entry (\%) & $8.1(0.8)$ & $8.1(0.7)$ & $8.1(0.7)$ \\
\hline Baseline HbAlc (\%) & $7.5(0.6)$ & $7.6(0.8)$ & $7.6(0.7)$ \\
\hline Fasting serum glucose $(\mathrm{mg} / \mathrm{dL})$ & $124.3(30.5)$ & $123.1(29.3)$ & $123.7(29.7)$ \\
\hline Metformin treatment, $n(\%)$ & $24(51.1)$ & $21(45.7)$ & $45(48.4)$ \\
\hline SGLT-2 inhibitor treatment, $n(\%)$ & $14(29.8)$ & $13(28.3)$ & $27(29.0)$ \\
\hline \multicolumn{4}{|l|}{ Bolus insulin at study entry, $n(\%)$} \\
\hline Aspart & $16(39.0)$ & $19(54.3)$ & $35(46.1)$ \\
\hline Glulisine & $10(24.4)$ & $6(17.1)$ & $16(21.1)$ \\
\hline Lispro $100 \mathrm{U} / \mathrm{mL}$ & $15(36.6)$ & $10(28.6)$ & $25(32.9)$ \\
\hline \multicolumn{4}{|l|}{ Basal insulin at baseline, $n$ (\%) } \\
\hline Degludec (QD) & $21(44.7)$ & $21(45.7)$ & $42(45.2)$ \\
\hline Glargine (QD) & $26(55.3)$ & $25(54.3)$ & $51(54.8)$ \\
\hline \multicolumn{4}{|l|}{ Prandial insulin dosing plan, $n(\%)$} \\
\hline Pattern adjustment & $46(97.9)$ & $46(100.0)$ & $92(98.9)$ \\
\hline Carbohydrate counting & $1(2.1)$ & $0(0)$ & $1(1.1)$ \\
\hline
\end{tabular}

Values in table are presented as the mean with the standard deviation (SD) in parenthesis, unless otherwise indicated $H b A 1 c$ Hemoglobin A1c, $n$ number of patients, $N$ number of patients, $Q D$ once daily, $S G L T-2$ sodium-glucose cotransporter-2, T2DM type 2 diabetes mellitus, URLi ultra-rapid lispro

\section{Self-Monitored Blood Glucose}

A time course of 10-point SMBG profiles at week 26 for both treatment groups is outlined in Fig. 4. At week 26, LSM differences for the morning postmeal glucose excursions were $-26.8 \mathrm{mg} / \mathrm{dL} \quad(95 \% \quad \mathrm{CI}-43.8$ to -9.8$)$ $(-1.49 \mathrm{mmol} / \mathrm{L})$ at $1 \mathrm{~h}$ postmeal and $-21.9 \mathrm{mg} / \mathrm{dL} \quad(95 \% \quad \mathrm{CI}-40.7$ to -3.1$)$ $(-1.22 \mathrm{mmol} / \mathrm{L})$ at $2 \mathrm{~h}$ postmeal; LSM differences for the midday postmeal glucose excursions were $-9.2 \mathrm{mg} / \mathrm{dL}$ (95\% CI -27.3 to 8.8 ) $(-0.51 \mathrm{mmol} / \mathrm{L})$ at $1 \mathrm{~h}$ postmeal and $-0.6 \mathrm{mg} /$
$\mathrm{dL}(95 \% \mathrm{CI}-21.1$ to 20.0$)(-0.03 \mathrm{mmol} / \mathrm{L})$ at $2 \mathrm{~h}$ postmeal; and LSM differences for the evening postmeal glucose excursions were - $\quad 13.3 \mathrm{mg} / \mathrm{dL} \quad(95 \% \quad \mathrm{CI}-34.2$ to 7.6$)$ $(-0.74 \mathrm{mmol} / \mathrm{L})$ at $1 \mathrm{~h}$ postmeal and $-8.4 \mathrm{mg} /$ dL $(95 \% \mathrm{CI}-28.6$ to 11.8$)(-0.47 \mathrm{mmol} / \mathrm{L})$ at $2 \mathrm{~h}$ postmeal.

Overall, daily average blood glucose levels in the 10-point SMBG profiles were similar between treatment groups, with the exception of significantly higher blood glucose levels in the lispro group compared to the URLi group at 


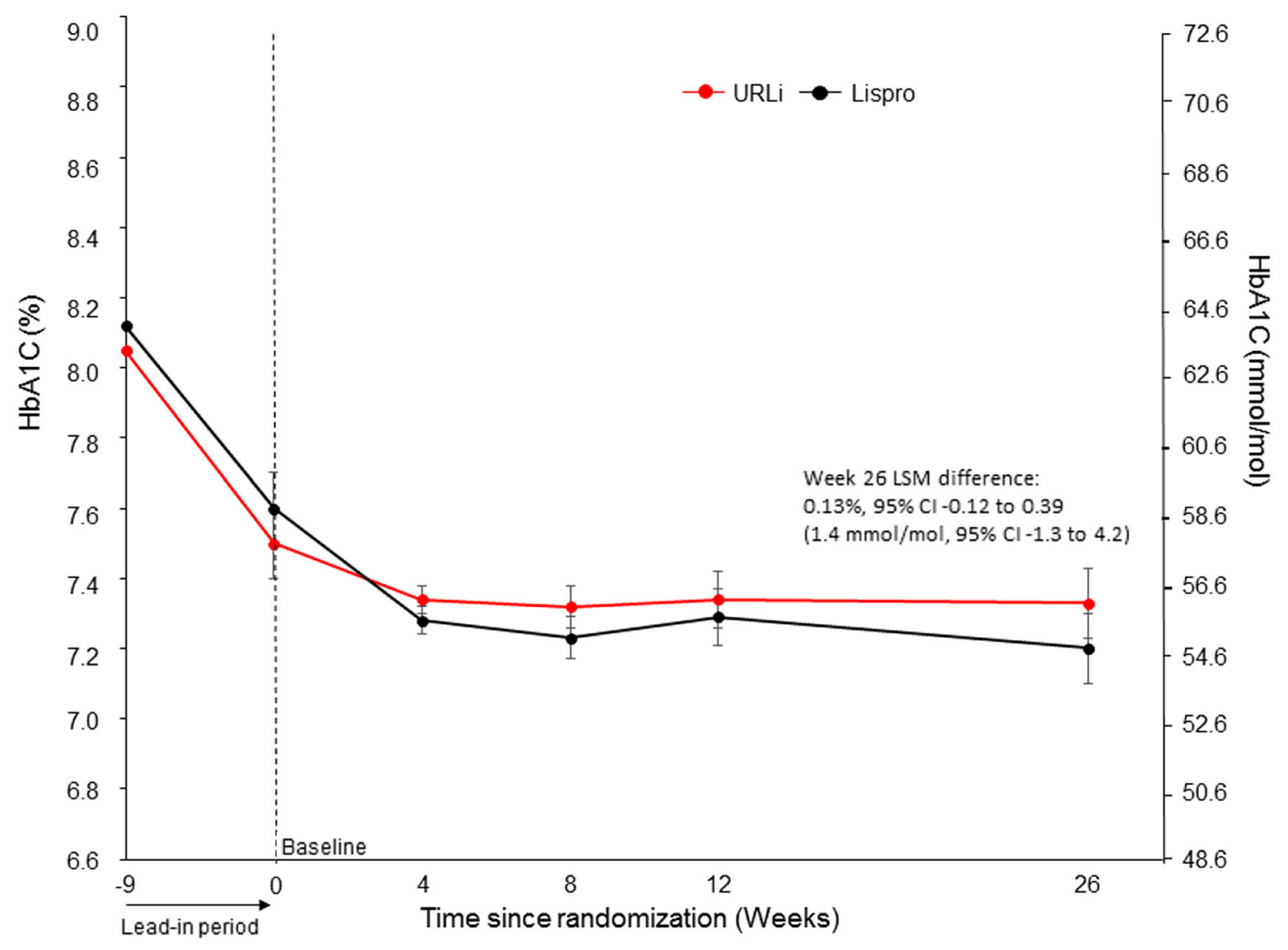

Fig. 2 Glycated hemoglobin $(H b A l c)$ profile by visit during the lead-in period and 26 weeks of treatment in Japanese patients. HbAlc levels for patients subsequently randomized to the URLi and lispro treatment arms during the lead-in period and from baseline to week 26 are given

the morning postmeal time-points of $1 \mathrm{~h}$ (LSM difference $-25.3 \mathrm{mg} / \mathrm{dL} \quad[-1.41 \mathrm{mmol} / \mathrm{L}]$, $p=0.001)$ and $2 \mathrm{~h}$ (LSM difference $-22.3 \mathrm{mg} /$ $\mathrm{dL}[-1.24 \mathrm{mmol} / \mathrm{L}], p=0.005)$ (Fig. 4 ).

\section{Insulin Dose}

The total daily basal insulin dose at baseline was $0.28 \mathrm{U} / \mathrm{kg}$ for URLi and $0.32 \mathrm{U} / \mathrm{kg}$ for lispro. At week 26, the daily basal insulin dose was $0.33 \mathrm{U} / \mathrm{kg}$ for both URLi and lispro. The ratio of prandial to total insulin dose at week 26 was similar between the URLi and lispro treatment groups (56 and 53\%, respectively; $p=0.663$ ). in percentage and in nanomoles per mole $(\mathrm{mmol} / \mathrm{mol})$. Data are presented as the mean at study entry and as the least squares mean $(L S M) \pm$ standard error $(S E)$ at all other time-points. CI Confidence interval

\section{Safety and Tolerability}

A summary of AEs is outlined in Table 2. Overall, the incidence of treatment-emergent AEs (TEAEs) related to the study treatment and SAEs was low, and similar for both treatment groups. In addition, the majority of the TEAEs related to the study treatment were mild and resolved without dose adjustment. There were no discontinuations from the study, or from study treatment, due to an AE. At week 26, mean change in body weight from baseline was $1.2 \mathrm{~kg}$ in the URLi treatment group and $1.3 \mathrm{~kg}$ in the lispro treatment group. 


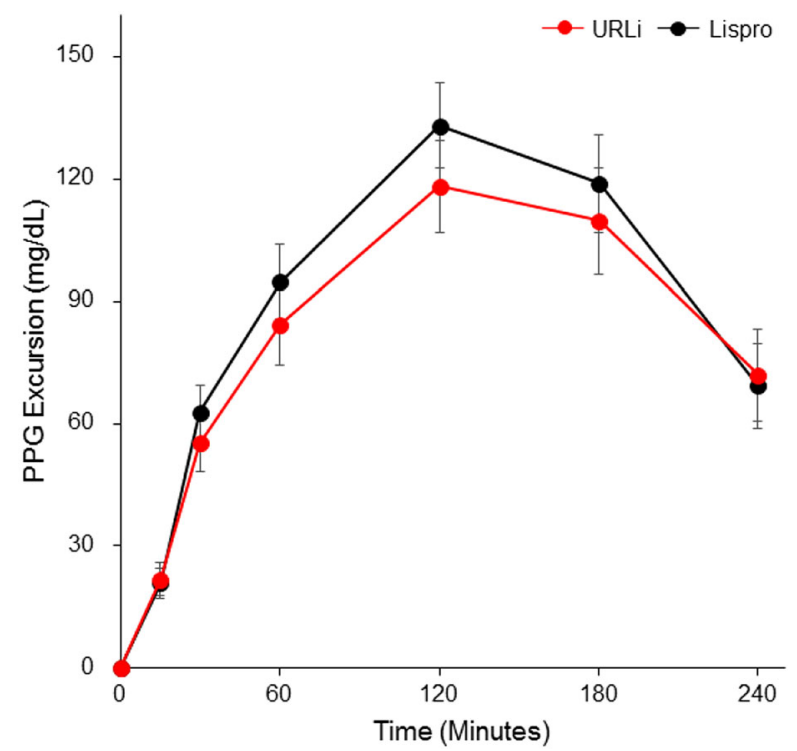

Fig. 3 Postprandial glycemic excursions during the MMTT at week 26 in Japanese patients. Postprandial glucose $(P P G)$ excursions $(\mathrm{mg} / \mathrm{dL})$ following URLi or lispro treatment at time-points ranging from $15 \mathrm{~min}$ to $4 \mathrm{~h}$ during the MMTT are shown. Data are presented as $\mathrm{LSM} \pm \mathrm{SE}$

During the 26-week treatment period, no severe hypoglycemia was observed, and there were no significant differences between treatment groups in the incidence of documented symptomatic hypoglycemia and in the rate and incidence of non-nocturnal hypoglycemia with glucose $<54 \mathrm{mg} / \mathrm{dL}$. The rate of documented symptomatic hypoglycemia (events/patients per 30 days) with glucose $<54 \mathrm{mg} / \mathrm{dL}$ was significantly higher in the URLi treatment group than in the lispro treatment group (Table 3 ).

The rate and incidence of postprandial hypoglycemia at the time-points of $\leq 2 \mathrm{~h}$ was statistically significantly higher in the URLi group than in the lispro group, but there were no significant differences in the late postprandial period ( $>4 \mathrm{~h}$ postmeal). No statistical differences were observed between the two treatments between 2 and $4 \mathrm{~h}$ (Fig. 5).

\section{DISCUSSION}

The PRONTO-T2D study demonstrated that URLi is non-inferior to lispro in terms of change in HbA1c following 26 weeks of treatment and that URLi is superior to lispro at reducing 1- and 2-h PPG excursions during the meal test [21]. In our subpopulation analysis of Japanese patients with T2DM, URLi demonstrated effective glycemic control when used in combination with basal insulin, with an acceptable safety profile. This is the first study to report the efficacy and safety of URLi compared to lispro in this patient population and provides valuable information for clinicians and policy-makers in Japan.

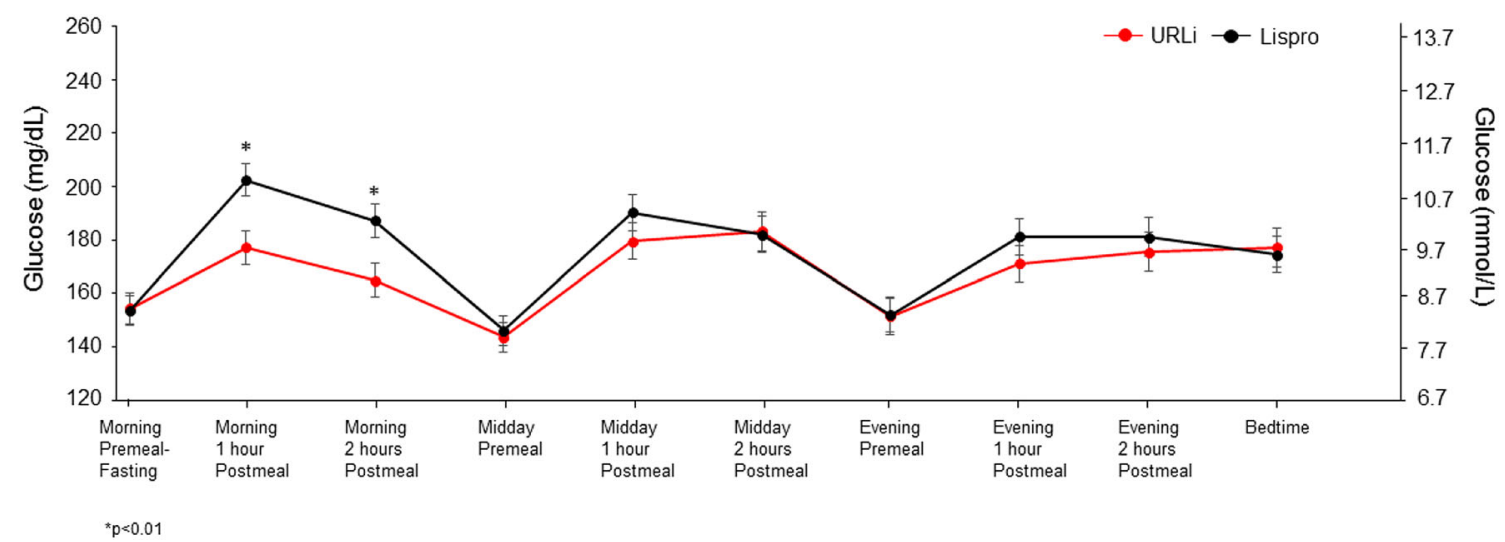

Fig. 4 Time course of 10-point self-monitored blood glucose $(\mathrm{SMBG})$ profile at week 26 in Japanese patients. SMBG profiles $(\mathrm{mg} / \mathrm{dL}$ and $\mathrm{mmol} / \mathrm{L})$ in URLi and lispro treatment groups are shown at the time-points of morning, midday, evening and bedtime. Data are presented as $\mathrm{LSM} \pm \mathrm{SE}$. Asteriks indicates time-points at which there was a significant difference $(p<0.01)$ between treatment groups 
Table 2 Summary of adverse events between week 0 and week 26 in the subpopulation of Japanese patients from the PRONTO-T2D trial

\begin{tabular}{lll}
\hline Adverse event & Treatment arm & \\
\cline { 2 - 3 } & URLi $(\boldsymbol{N}=\mathbf{4 7})$ & Lispro $(\boldsymbol{N}=\mathbf{4 6})$ \\
\hline Treatment-emergent adverse events & $31(66.0)$ & $25(54.3)$ \\
Treatment-emergent adverse events related to study treatment ${ }^{\mathrm{a}}$ & $4(8.5)$ & $2(4.3)$ \\
Injection site pain & $2(4.3)$ & $0(0)$ \\
Myalgia & $1(2.1)$ & $0(0)$ \\
Asthma & $1(2.1)$ & $0(0)$ \\
Diabetic retinopathy & $0(0)$ & $1(2.2)$ \\
Muscle spasm & $0(0)$ & $1(2.2)$ \\
Serious adverse events & $4(8.5)$ & $1(2.2)$ \\
Discontinuation from study treatment due to an adverse event & $0(0)$ & $0(0)$ \\
Discontinuation from study due to an adverse event & $0(0)$ & $0(0)$ \\
Deaths & $0(0)$ & $0(0)$ \\
\hline
\end{tabular}

Values in table are presented as a number with the percentage in parenthesis. Patients may be counted in more than one category

$n$ Number of patients, $N$ number of patients

${ }^{a}$ Events that were considered to be related to study treatment as judged by the investigator

Table 3 Summary of hypoglycemia events between week 0 to week 26 in the subpopulation of Japanese patients from the PRONTO-T2D trial

\begin{tabular}{lll}
\hline Characteristic & \multicolumn{2}{l}{ Treatment arm } \\
\cline { 2 - 3 } & $\begin{array}{l}\text { URLi } \\
(\boldsymbol{N}=47)\end{array}$ & $\begin{array}{l}\text { Lispro } \\
(\boldsymbol{N}=46)\end{array}$ \\
\hline Severe hypoglycemia, $n(\%)$ & $0(0)$ & $0(0)$ \\
Documented symptomatic hypoglycemia with glucose $<54 \mathrm{mg} / \mathrm{dL}, n(\%)$ & $16(34.0)$ & $9(19.6)$ \\
Rate of documented symptomatic hypoglycemia with glucose $<54 \mathrm{mg} / \mathrm{dL}$, events/patients/ & $0.32(0.12)^{*}$ & $0.05(0.02)$ \\
30 days, LS mean $(\mathrm{SE})$ & & \\
$\begin{array}{l}\text { Non-nocturnal hypoglycemia with glucose }<54 \mathrm{mg} / \mathrm{dL}, n(\%) \\
\text { Rate of non-nocturnal hypoglycemia with glucose }<54 \mathrm{mg} / \mathrm{dL}, \text { events/patients/year, LS } \\
\text { mean (SE) }\end{array}$ & $7.37(1.9)$ & $4.74(1.4)$ \\
\hline
\end{tabular}

$L S$ Least squares, $N$ number of subjects in the population with baseline and post-baseline values at the specified time-point, $n$ number of subjects with hypoglycemia, $S E$ standard error

${ }^{*}$ Significant difference at $p<0.05$ between URLi and lispro treatment groups 

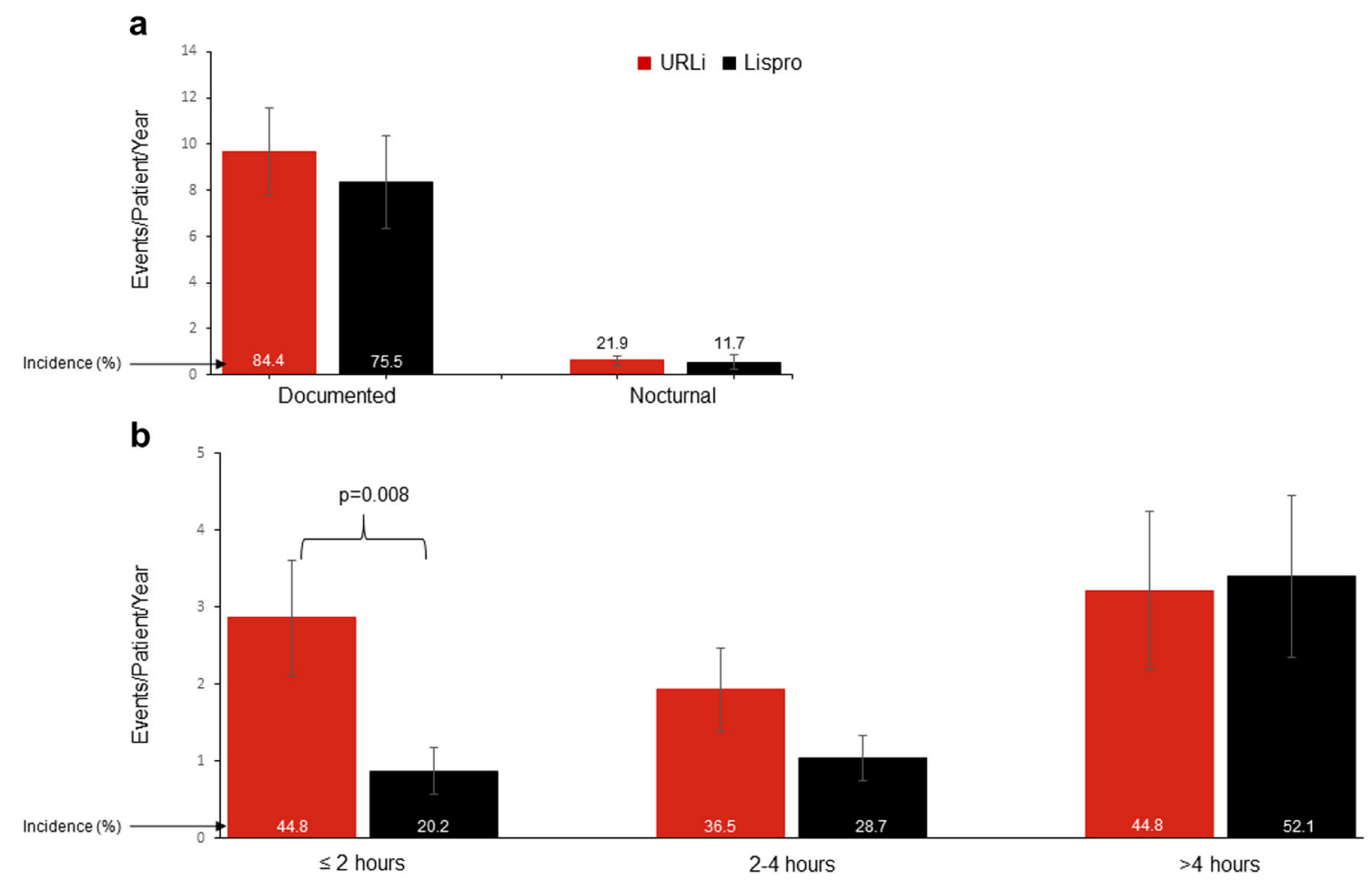

Fig. 5 Incidence and rate of hypoglycemia (with or without symptoms) from week 0 to week 26 in Japanese patients. Rate and incidence of documented and nocturnal hypoglycemia (blood glucose $[B G]<54 \mathrm{mg} / \mathrm{dL}$ ) (a) and

As shown in the overall PRONTO-T2D study population, in this Japanese subpopulation URLi was comparable to lispro in terms of change in mean HbA1c levels. The upper limit of $95 \%$ CI of LSM differences between mealtime dosing of URLi and mealtime dosing of lispro was $<0.4 \%$, which was the prespecified noninferiority margin for the overall population [21]. Overall, consistent HbA1c profiles were observed between Japanese patients and the overall PRONTO-T2D study population, from study entry through week 26 .

In the overall PRONTO-T2D patient population, URLi treatment was statistically significantly better at controlling PPG excursions during a MMTT in comparison to lispro at 1 and $2 \mathrm{~h}$ postmeal at week 26 [21]. This finding reflects the fast onset and short duration of action observed in URLi clinical pharmacology studies [23, 24]. In this Japanese patient subpopulation, we observed a consistent numerical trend for a PPG reduction with URLi treatment symptomatic and asymptomatic postmeal hypoglycemia $(\mathrm{BG}<54 \mathrm{mg} / \mathrm{dL})(\mathbf{b})$. Data are presented as LSM + SE for event rate and LSM for incidence

in comparison to lispro from $30 \mathrm{~min}$ to $3 \mathrm{~h}$ following the MMTT. This observation is consistent with the findings in the overall population, in which the higher number of patients resulted in statistically significant PPG reductions [21]. The small number of Japanese patients limited the likelihood of obtaining the consistent statistical differences observed in the whole study population [21].

Overall, the daily average blood glucose levels in the 10-point SMBG profiles were similar between treatments, with the exception of blood glucose levels at the morning postmeal time-points of 1- and 2-h where the URLi treatment group showed lower PPG levels compared with the lispro treatment group. Importantly, the ratio of prandial to total insulin dose at week 26 was similar between the two groups. The SMBG results observed in this subgroup analysis is consistent with the SMBG profiles observed in the overall population where 10-point SMBG testing demonstrated 
improved PPG control with significantly lower PPG levels after the morning meal and reduced daily mean PPG levels and excursions in the URLi group compared with the lispro group [21].

An important observation is that the overall trend in PPG excursions in the MMTT was consistent between the Japanese subpopulation and the overall PRONTO-T2D study population. In this exploratory analysis of Japanese patients, we observed consistently numerically smaller PPG excursions from $30 \mathrm{~min}$ to $3 \mathrm{~h}$ during the MMTT for mealtime URLi compared to lispro; LSM differences were $-10.5 \mathrm{mg} / \mathrm{dL}$ at $1 \mathrm{~h}$ postmeal and $-14.9 \mathrm{mg} / \mathrm{dL}$ at $2 \mathrm{~h}$ postmeal. By comparison, the estimated treatment differences between mealtime URLi and lispro for the overall population were $-110.8 \mathrm{mg} / \mathrm{dL}$ at $1 \mathrm{~h}$ postmeal and $-17.4 \mathrm{mg} / \mathrm{dL}$ at $2 \mathrm{~h}$ postmeal [21].

Overall, URLi was well tolerated by Japanese patients. The incidence of SAEs and TEAEs related to the study treatment was low and similar across treatment groups. Furthermore, there were no discontinuations from the study due to an $\mathrm{AE}$, and no deaths.

It is well established that achieving glycemic control, as determined by HbA1c levels, is effective in reducing the risk of diabetes complications. In addition, epidemiology studies indicate elevated PPG levels increase the risk of cardiovascular disease [10, 25-28] and that controlling PPG excursions is essential for achieving recommended HbA1c goals $[29,30]$. In comparison to lispro, URLi may not only mimic the time-action profile of normal insulin secretion more closely, but it may also lower PPG excursions, with an acceptable safety profile, as described in the PRONTO-T2D trial [21]. Following approval in Europe [31], URLi was recently granted approval in Japan (March 2020) under the trade name Lyumjev [32].

A limitation of the study design is that the MMTT insulin dose may not have been fit for Japanese patients who were relatively lighter compared to patients in the overall population. As mentioned above, the 500-rule was used to calculate the MMTT insulin dose for the majority of Japanese patients on the pattern adjustment method, and one limitation of the 500-rule method is it does not account for body weight. In addition, the small number of patients in this subpopulation analysis limited the likelihood of obtaining statistical differences in this population.

\section{CONCLUSION}

In conclusion, the results of this 26-week trial indicates that URLi is effective and comparable to lispro in terms of overall glycemic control when administered immediately before a meal in Japanese patients with T2DM. Furthermore, URLi was well tolerated, with an acceptable safety profile in this population.

\section{ACKNOWLEDGEMENTS}

We thank the patients and their families/caregivers, the study investigators and their staff, and the PRONTO-T2D clinical trial team.

Funding. This study was sponsored by Eli Lilly and Company (Indianapolis, IN, USA). This subpopulation analysis, including the Rapid Service Fee, was sponsored by Eli Lilly Japan K.K. (Kobe, Japan). All authors had full access to all of the data in this study and take complete responsibility for the integrity of the data and accuracy of the data analysis.

Medical Writing, Editorial and Other Assistance. Medical writing support was provided by Lisa Cossens, and editorial support by Dana Schamberger and Likhitha Kurma, of Syneos Health, and funded by Eli Lilly Japan K.K. Project management support was provided by Aki Yoshikawa from Eli Lilly Japan K.K.

Authorship. All named authors meet the International Committee of Medical Journal Editors (ICMJE) criteria for authorship for this article, take responsibility for the integrity of the work as a whole, and have given their approval for this version to be published.

Disclosures. Makoto Imori, Hiroshi Nishiyama, and Takeshi Imaoka are employees of Eli Lilly Japan K.K. and minor stockholders of Eli 
Lilly and Company. Hideaki Jinnouchi declares honoraria for lectures for MSD.K.K., Astellas Pharma Inc., Sanofi K.K., Novo Nordisk Pharma Ltd., Taisho Pharma Co., Ltd., DaiichiSankyo Co., Ltd., Nippon Boehringer Ingelheim Co., Ltd., Sumitomo Dainippon Pharma Co., Ltd. and Eli Lilly Japan K.K.

Compliance with Ethics Guidelines. The study was conducted in accordance with the International Council for Harmonization Guidelines for Good Clinical Practice including the Declaration of Helsinki and its later amendments and the Council for International Organisation of Medical Sciences International Ethical Guidelines. An Ethical Review Board at each site (Kobori Clinic, H.E.C. Science Clinic, Jinnouchi Hospital, Heiwadai Hospital, The Institute for Adult Diseases, Naka Memorial Clinic, Tomonaga Clinic, Nihonbashi Sakura Clinic, AMC Nishi-umeda Clinic, Manda Hospital, Fukuoka Red Cross Hospital, Shin Akasaka Clinic, Shinagawa East One Medical Clinic, Sasebo Chuo Hospital, Okuguchi Clinic of Internal Medicine, Sapporo Skin Clinic, Takatsuki Red Cross Hospital, Osaka City University Medical School Hospital, Goshogatani Home Clinic, Tokyo Women's Medical University Hospital) approved all procedures, and all subjects provided written, informed consent.

Data Availability. Eli Lilly and Company provides access to all individual participant data collected during the trial, after anonymization, with the exception of pharmacokinetic or genetic data. Data are available to request 6 months after the indication studied has been approved in the USA and EU and after primary publication acceptance, whichever is later. No expiration date of data requests is currently set once data are made available. Access is provided after a proposal has been approved by an independent review committee identified for this purpose and after receipt of a signed data sharing agreement. Data and documents, including the study protocol, statistical analysis plan, clinical study report and blank or annotated case report forms, will be provided in a secure data-sharing environment. For details on submitting a request, see the instructions provided at www.vivli.org.

Open Access. This article is licensed under a Creative Commons Attribution-NonCommercial 4.0 International License, which permits any non-commercial use, sharing, adaptation, distribution and reproduction in any medium or format, as long as you give appropriate credit to the original author(s) and the source, provide a link to the Creative Commons licence, and indicate if changes were made. The images or other third party material in this article are included in the article's Creative Commons licence, unless indicated otherwise in a credit line to the material. If material is not included in the article's Creative Commons licence and your intended use is not permitted by statutory regulation or exceeds the permitted use, you will need to obtain permission directly from the copyright holder. To view a copy of this licence, visit http://creativecommons.org/licenses/by$\mathrm{nc} / 4.0 /$.

\section{REFERENCES}

1. World Health Organization (WHO). Global report on diabetes 2016. Geneva: WHO; 2016. https:// www.who.int/diabetes/global-report/en/. Accessed 11 Mar 2020.

2. Stark Casagrande S, Fradkin JE, Saydah SH, Rust KF, Cowie CC. The prevalence of meeting A1C, blood pressure, and LDL goals among people with diabetes, 1988-2010. Diabetes Care. 2013;36:2271-9.

3. American Diabetes Association. Standards of medical care in diabetes-2019. Abridged for primary care providers. Clin Diabetes. 2019;37:11-34.

4. Goto A, Noda $M$, Inoue $M$, Goto $M$, Charvat $H$. Increasing number of people with diabetes in Japan: is this trend real? Intern Med. 2016;55:1827-30.

5. Japan Diabetes Clinical Data Management Study Group. Fundamental Statistics in 2017. https:// jddm.jp/data/index-2017.html\#data_03. Accessed 11 Mar 2020.

6. Monnier L, Lapinski H, Colette C. Contributions of fasting and postprandial plasma glucose increments to the overall diurnal hyperglycemia of type 2 
diabetic patients: variations with increasing levels of $\mathrm{HbA}(1 \mathrm{c})$. Diabetes Care. 2003;26:881-5.

7. Standl E, Schnell O, Ceriello A. Postprandial hyperglycemia and glycemic variability: should we care? Diabetes Care. 2011;34(Suppl 2):S120-S127.

8. Madsbad S. Impact of postprandial glucose control on diabetes-related complications: how is the evidence evolving? J Diabetes Complicat. 2016;30: 374-85.

9. DECODE Study Group, the European Diabetes Epidemiology Group. Glucose tolerance and cardiovascular mortality: comparison of fasting and 2-hour diagnostic criteria. Arch Intern Med. 2001;161:397-405.

10. Meigs JB, Nathan DM, D'Agostino RB Sr, Wilson PW. Fasting and postchallenge glycemia and cardiovascular disease risk: the Framingham Offspring Study. Diabetes Care. 2002;25:1845-50.

11. Hanefeld M, Fischer S, Julius U, et al. Risk factors for myocardial infarction and death in newly detected NIDDM: the Diabetes Intervention Study, 11-year follow-up. Diabetologia. 1996;39:1577-83.

12. Brod M, Nikolajsen A, Weatherall J, et al. Understanding post-prandial hyperglycemia in patients with type 1 and type 2 diabetes: a web-based survey in Germany, the UK, and USA. Diabetes Ther. 2016;7:335-48.

13. Pfeiffer KM, Sandberg A, Nikolajsen A, et al. Postprandial glucose and healthcare resource use: a cross-sectional survey of adults with diabetes treated with basal-bolus insulin. J Med Econ. 2018;21: 66-73.

14. Boss AH, Petrucci R, Lorber D. Coverage of prandial insulin requirements by means of an ultra-rapidacting inhaled insulin. J Diabetes Sci Technol. 2012;6:773-9.

15. Heinemann L, Hompesch $M$, Flacke $F$, et al. Reduction of postprandial glycemic excursions in patients with type 1 diabetes: a novel human insulin formulation versus a rapid-acting insulin analog and regular human insulin. J Diabetes Sci Technol. 2011;5:681-6.

16. Hompesch M, Muchmore DB, Morrow L, et al. Accelerated insulin pharmacokinetics and improved postprandial glycemic control in patients with type 1 diabetes after coadministration of prandial insulins with hyaluronidase. Diabetes Care. 2011;34:666-8.

17. Krasner A, Pohl R, Simms P, et al. A review of a family of ultra-rapid-acting insulins: formulation development. J Diabetes Sci Technol. 2012;6: 786-96.

18. Andersen G, Meiffren G, Lamers D, et al. Ultra-rapid BioChaperone Lispro improves postprandial blood glucose excursions vs insulin lispro in a 14-day crossover treatment study in people with type 1 diabetes. Diabetes Obes Metab. 2018;20:2627-32.

19. Kitabchi AE, Gosmanov AR. Safety of rapid-acting insulin analogs versus regular human insulin. Am J Med Sci. 2012;344:136-41.

20. Eli Lilly and Company. Humalog (prescribing information); 2015. https://pi.lilly.com/us/ humalog-pen-pi.pdf. Accessed 25 Mar 2020.

21. Blevins T, Zhang Q, Frias JP, et al. Ultra rapid lispro improves postprandial glucose control vs. lispro in patients with type 2 diabetes: PRONTO-T2D. Diabetes Care. 2020. https://doi.org/10.2337/dc192550 .

22. World Health Organization (WHO). Classification of diabetes mellitus. Geneva:WHO; 2019. https:// www.who.int/publications-detail/classification-ofdiabetes-mellitus. Accessed 11 Mar 2020.

23. Leohr J, Dellva MA, Carter K, et al. 1040-P Ultrarapid lispro (URLi) accelerates insulin lispro absorption and insulin action vs. humalog (lispro) consistently across study populations: a metaanalysis of pharmacokinetic and glucodynamic data. Diabetes 2020; 69(Supplement 1).https://doi. org/10.2337/db20-1040-P.

24. Linnebjerg H, Zhang Q, LaBell E, et al. 1107-P: ultra rapid lispro (URLi) accelerates insulin lispro absorption and insulin action vs. Humalog® (lispro) in patients with T1D. Diabetes. 2019;68:(Suppl 1).

25. DECODE Study Group, European Diabetes Epidemiology Group. Is the current definition for diabetes relevant to mortality risk from all causes and cardiovascular and noncardiovascular diseases? Diabetes Care. 2003;26:688-96.

26. Coutinho M, Gerstein HC, Wang Y, Yusuf S. The relationship between glucose and incident cardiovascular events: A metaregression analysis of published data from 20 studies of 95,783 individuals followed for 12.4 years. Diabetes Care. 1999;22: 233-40.

27. Cavalot F, Petrelli A, Traversa M, et al. Postprandial blood glucose is a stronger predictor of cardiovascular events than fasting blood glucose in type 2 diabetes mellitus, particularly in women: lessons from the San Luigi Gonzaga Diabetes Study. J Clin Endocrinol Metab. 2006;91:813-9. 
28. Ceriello A, Davidson J, Hanefeld M, et al. Postprandial hyperglycaemia and cardiovascular complications of diabetes: an update. NMCD. 2006;16: 453-6.

29. Ketema EB, Kibret KT. Correlation of fasting and postprandial plasma glucose with HbA1c in assessing glycemic control; systematic review and metaanalysis. Arch Public Health. 2015;73:43.

30. Woerle HJ, Neumann C, Zschau S, et al. Impact of fasting and postprandial glycemia on overall glycemic control in type 2 diabetes Importance of postprandial glycemia to achieve target HbA1c levels. Diabetes Res Clin Pract. 2007;77:280-5.

31. European Medicines Agency. Liumjev https://www. ema.europa.eu/en/medicines/human/EPAR/liumje v\#authorisation-details-section. Accessed 2 June 2020.

32. Pharmaceutical and Medical Devices Agency. Summary of investigaition results. Preparations containing insulin. https:/www.pmda.go.jp/files/ 000235075.pdf\#page $=4$. Accessed 2 June 2020 . 